\title{
Simultaneous measurements of burning velocity and temperature distribution of combustion using UV laser Rayleigh scattering
}

\author{
Seong-Ho Jin* \\ School of Engineering \\ University of Lincoln \\ Lincoln, LN6 7TS, UK \\ Gyung-Soo Kim \\ Korea Institute of Industrial Technology \\ Chonan, 330-825, Korea
}

\begin{abstract}
Planar temperature images using laser Rayleigh scattering have been obtained to determine the spatial distribution of temperature in a constant volume combustion chamber. Burning velocities were also measured from measured pressures and calculated flame surface area from Rayleigh scattering images. A high power $\mathrm{KrF}$ excimer laser was used as a light source and a high gain ICCD camera was used to obtain temperature images. Methane/air premixed combustion at different equivalence ratios and initial pressures were tested. Since the thermodynamics are well known, a constant volume chamber can be used as a reference device for diagnostics in high temperatures and pressures combustion. With the Rayleigh scattering technique, temperature and burning velocity can be measured simultaneously using a single-shot laser light. An additional laser Rayleigh experiment is described which yields scattering cross sections at the wavelength of $248 \mathrm{~nm}$. The experimental results show an excellent agreement with previous data.
\end{abstract}

Keywords: Burning velocity; Rayleigh scattering; Constant volume combustion chamber; Premixed combustion

\footnotetext{
* Corresponding author, email: sjin@lincoln.ac.uk
} 


\section{NOMENCLATURE}

\section{$\underline{\text { Roman }}$}

Af : surface area of the flame front

$k, k^{\prime} \quad$ : optical constant

$I_{o} \quad:$ laser energy

$m$ : mass

$M \quad$ : molecular weight

$n \quad:$ molecular number density

$P \quad:$ pressure

$R \quad$ : gas constant or radius

$S \quad$ : Rayleigh scattering signal intensity

$S_{L} \quad$ : laminar burning velocity

$S_{F} \quad$ : flame propagation speed

$t \quad:$ time

$T \quad$ : temperature

$v \quad:$ specific volume

$V \quad$ : volume

$x \quad$ : mole fraction or Cartesian coordinate

$y \quad$ : mass fraction or Cartesian coordinate

$z \quad$ : volume fraction or Cartesian coordinate

\section{Greek}

$\alpha \quad$ : molecule polarizability

$\sigma \quad$ : Rayleigh scattering cross section

$\phi \quad$ : equivalence ratio (actual fuel/air ratio over ideal fuel/air ratio)

$\lambda \quad$ : wavelength

\section{$\underline{\text { Subscripts }}$}

$\begin{array}{ll}b & : \text { burned } \\ i & : \text { species } \\ \text { eff } & : \text { effective } \\ u & : \text { unburned }\end{array}$

\section{Abbreviations}

a.u. : arbitrary unit

EQ : equivalence ratio

int. : initial

press. : pressure

RS : Rayleigh scattering

UV : ultra violet 


\section{INTRODUCTION}

The species density, combustion temperature, pressures and burning velocity are the most fundamental thermodynamic properties which characterise combustion with different fuel/air mixtures. Knowledge of these parameters has practical importance in the design and analysis of practical combustion devices, such as automotive engines, gas turbines and industrial burners. Basic chemical kinetic models have been developed for predicting the end result of the combustion process, as have computer simulations. Although they play an increasingly important role in design and optimisation procedures, such models and their calculations are complex and should be validated.

The thermodynamic phenomena inside the combustion chambers have been discussed in the previous researches, and burning velocities were measured using the laser diffraction method by schlieren photography in a spherical chamber that was ignited at its centre [1-6].

Laser-based Rayleigh scattering technique has been developed for temperature measurements. It has been applied to thermometry in combustion and is excellent method for this purpose. It does not require any seeding materials and can provide two dimensional information in all regions of the flame, while other techniques measure temperature at a single point $[7,8]$. The signal intensity of Rayleigh scattering is relatively low but usually sufficient for measurements in high temperature environments, and the data evaluation is straightforward [9-11].

However, both the laser diffraction and laser-based Rayleigh scattering techniques are only for single parameter measurement such as burning velocity or temperature. This paper discusses an application of the laser-based Rayleigh scattering technique to a constant volume combustion chamber. Simultaneous measurements of several laminar burning velocities and two dimensional temperature images of the burned and unburned zones inside the chamber at 
different equivalence ratios and initial pressures are presented using single-shot UV laser Rayleigh scattering.

In this research, methane was used as a fuel. The chamber deals with laminar combustion and is a simplified version of practical combustion apparatus. The results can help to verify the experimental method and evaluate how it might be used in practical combustion devices. In addition to the quantitative calculation, quantitative visualisation gives direct information of the temperature distribution and the rate of flame propagation. The results can be also used in practical applications to verify theoretical models and computer simulations.

\section{EXPERIMENT}

The constant volume combustion chamber had a circular cylinder shape and consisted of stainless steel. The chamber is $100 \mathrm{~mm}$ long with an $80 \mathrm{~mm}$ bore. There were four fused quartz windows for optical access. Two of them were used for transmitting the laser beam through the chamber and were located on the cylinder wall while the other two for detecting the emitted light and were on the two ends of the cylinder. The total inner volume of the chamber was $559 \mathrm{~cm}^{3}$. A spark plug was placed on the bottom wall to initiate the combustion. A piezoelectric pressure transducer (Kistler, 6051B, error $\pm 1 \%$ ) measured the pressure change during combustion. The transducer was calibrated by a dead weight tester. The pressure was recorded via a charge amplifier (Kistler, 5011) to an oscilloscope (LeCroy, 9354A) which was interfaced to a computer. The schematic of the chamber set-up is shown in Fig. 1.

A KrF excimer laser (Lambda Physik, COMPex 205) which had an output energy of $450 \mathrm{~mJ}$ and a wavelength of $248 \mathrm{~nm}$ was used as a light source. A sheet beam of $0.1 \mathrm{~mm} \times$ 
$20 \mathrm{~mm}$ is formed using two cylindrical lenses. The shot-to-shot fluctuation of the laser light was measured and recorded using a laser energy meter (Coherent, J-50MUV-248) before the chamber. The Rayleigh scattering images were then normalised by laser energy in order to eliminate error from the fluctuations. The optical system is aligned to minimise unwanted stray light such as Mie scattering and reflections from the chamber wall.

The scattered light emitting from combustion is imaged onto an ICCD camera (Princeton Instruments, 576G/RB-E). This camera has an intensity resolution of 16 bits per pixel. It operates in standard video mode. The gate on the intensifier is synchronised with the laser and the spark plug. The image is taken through a macro lens (UV-Nikkor $105 \mathrm{~mm}$, $f / \# 4.5)$ which places to the laser sheet perpendicularly. The spatial resolution of the images is $0.3 \mathrm{~mm}$ per pixel. The intensifier gate with a width of $100 \mathrm{~ns}$ suppresses almost all spontaneous emission from the combustion.

A single pulse laser beam with high power generates a two dimensional image. The image is recorded and digitised on a computer. It is presented in real time, either in false colours or in grey scales, on a monitor. Some inter-image operations, such as background subtraction, normalisation and density/temperature calculation, can be done directly on the computer.

The chamber is evacuated with a vacuum pump after combustion completed. The initial temperature inside the chamber is maintained at room temperature before ignition. The fresh fuel/air mixture is then injected to the chamber until the pressure reaches the initial pressure. The fuel/air mixture equilibrates in a separate premixing chamber and becomes a quiescent homogeneous state in advance. The timing of the system, spark plug ignition timing, laser trigger and ICCD camera gate synchronous timing are controlled by a timedelay pulse generator (Stanford Research Systems, Inc., DG-535). 


\section{RESULTS AND DISCUSSION}

\subsection{Burning velocity in constant volume combustion chamber}

The burning velocities were measured directly from measured pressures and RS images in a previous study [12]. Two different burning velocities are presented in this study. The first is the laminar burning velocity $S_{L}$. It is the speed at which unburned gas moves normally into the flame front and is changed to the products. Let $A_{f}$ be the surface area of the flame front, then $S_{L}=v_{u}(d m / d t) / A f$. This expression can be transformed to

$$
S_{L}=\left(\frac{d P}{d t}\right) \cdot \frac{V}{P \cdot A_{f}} \cdot \frac{1}{\left(v_{b} / v_{u}\right)-1}
$$

The detail expression of the laminar burning velocity can be found in a reference book [13]. $S_{L}$ is evaluated using measured values of $V, P, d P / d t$ and using the expansion ratio $v b / v_{u}$. The expansion ratio is $v_{b} / v_{u}=\left(T_{b} / M_{b}\right) /\left(T_{u} / M_{u}\right)$ which is calculated by the chemical equilibrium program, STANJAN [14]. Table 1 shows the calculated data using the STANJAN program.

$A_{f}$ is calculated by solving a geometric problem considering a hemisphere and a rightcircular cylinder. The base of the hemisphere and the curved wall are intersected. They are placed so that the line formed by the plane and the cylinder wall passes through the centre of the hemisphere's base. Details are presented in the appendix.

Then the top of the hemisphere is on the cylinder's axis and $A_{f}$ is proportional to the hemisphere's area that lies inside the cylinder. The analytic solution produces an elliptic 
integral that is evaluated numerically. The flame surface boundary is determined by image processing, by finding the maximum temperature gradient in the RS images.

The second velocity is $S_{F}$, the expansion speed of the burned gas, which differs from $S_{L}$ because the large ratio $v_{b} / v_{u}$ pushes the flame front outward. Here $\mathrm{S}_{F}=\left(d V_{b} / d t\right) / A f$, where $V_{b}$ $=z_{b} V=m y_{b} v_{b}$, and $z_{b}=1 /\left[\left(v_{u} / v_{b}\right)\left(y_{b}-1\right)+1\right]$, the volume fraction of the burned gases. By suitable manipulation of the equations, it can be shown that

$$
\frac{S_{F}}{S_{L}}=\frac{v_{b}}{v_{u}}(1-z b)+z b
$$

so $S_{F} \approx S_{L}\left(v_{b} / v_{u}\right)$ and $S_{F} \approx S_{L}$ for $z_{b} \approx 0$ and $z_{b} \approx 1$, respectively.

$S_{L}$ is determined through Eq. (1). The results are plotted in Fig. 2 and Fig. 3. The solid and dashed curves are the calculated burning velocities using the GRI chemical reaction mechanism, version 2.1 and $3.0[15,16]$ at different pressures. The results show that the experimental laminar burning velocities agree with the calculated results using CHEMKIN-II and PREMIX simulation code [17-19] and the other experimental results [20] within the error range of $\pm 3 \%$. The errors occur due to the asymmetric flame surface, uncertainty in determining the flame front etc.

$S_{L}$ is obtained in the chamber at various equivalence ratios. The measured values of $d P / d t$ and $P$ are $68.360 \mathrm{bar} / \mathrm{s}$ and $2.311 \mathrm{bar}$, respectively, at $\phi=1.0$. The calculated $v_{b}=$ $3.430 \mathrm{~m}^{3} / \mathrm{kg}$ and $v_{u}=0.424 \mathrm{~m}^{3} / \mathrm{kg}$. Then, from Eq. (1), $S_{L} \approx 31.2 \mathrm{~cm} / \mathrm{s}$. For the other $\phi$ in Table $1, P$ is $2.186 \pm 0.13 \mathrm{bar}, T_{u}$ is $325 \pm 7 \mathrm{~K}$, and $T_{b}$ ranges from $2211 \mathrm{~K}$ to $2615 \mathrm{~K}$. 
Alternatively, Eq. (2) can be applied after direct measurement of $S_{F}$ via flame front observation from RS images for different times. This is presented in Fig. 4. The results show that flame propagation speed, $S_{F}$, is within the range between $S_{L}$ and $S_{L}\left(v b / v_{u}\right)$.

\subsection{Temperature images in constant volume combustion chamber}

The RS signal intensity $S$ from laser light at a given wavelength, distance and angle of observation, is $I_{o} \cdot n \cdot \sigma_{\text {eff. }}$. Here, $\sigma_{\text {eff }}$ is an effective normalised RS cross section defined as $\Sigma$ $x_{i} \sigma_{i N}$, where $\sigma_{i N}\left(\equiv \sigma_{i} / \sigma_{N 2}\right)$, is a RS cross section for species $i$ that is normalised to that of $\mathrm{N}_{2}$. The strong wavelength dependence of the RS $\left(\lambda^{-4}\right)$ means that shorter wavelengths (UV) are scattered more strongly than longer wavelengths (visible light). It enables single-shot measurement using UV laser light.

The total number density distribution $n(x, y)$ is determined by

$$
n(x, y)=\frac{S(x, y)}{k \cdot I_{o}(x, y) \cdot \sigma_{\text {eff }}(x, y)}
$$

in which $S(x, y)$ is the two dimensional RS signal intensity from the images. For an ideal gas at uniform pressure, the temperature distribution is

$$
T(x, y)=\frac{k^{\prime} \cdot I_{o}(x, y) \cdot \sigma_{e f f}(x, y)}{S(x, y)}
$$

Then, the burned and unburned regions in the image are compared. For example, the unburned $\mathrm{CH}_{4} /$ air region in the chamber at $T_{u}$ serves as a reference. Let $\sigma_{u}$ and $\sigma_{b}$ represent 
$\sigma_{e f f}$ in the regions containing the unburned fuel/air mixture and the burned products, respectively. Then

$$
T_{b}(x, y)=T_{u}\left[\frac{\sigma_{b}(x, y)}{\sigma_{u}(x, y)}\right]\left[\frac{S_{u}(x, y)}{S_{b}(x, y)}\right]
$$

The values of $\sigma_{\text {eff }}$ for the burned gas are calculated from the $x_{i}$ obtained from thermodynamic equilibrium software, STANJAN [14]. Table 1 shows actual $x_{i}$ calculated. The mole fraction $x_{i}$ of major species $\left(\mathrm{N}_{2}, \mathrm{O}_{2}, \mathrm{CO}_{2}, \mathrm{H}_{2} \mathrm{O}\right.$ and $\left.\mathrm{CH}_{4}\right)$ was only used for the values of $\sigma_{e f f}$ due to unavailability of RS cross section of minor species such as $\mathrm{H}, \mathrm{NO}, \mathrm{O}$, $\mathrm{OH}$ etc. It leads some degree of uncertainty for actual values of $\sigma_{\text {eff. }}$. The $\sigma_{\text {eff }}$ at $248 \mathrm{~nm}$ obtained from $\sigma_{i N}$ listed in Table 2, were used in comparison with data from Kock et. al. [21]. The $\sigma_{i N}$ of each gas was measured in a separate experiment. In this experiment, the pure gases were filled in the chamber at various pressures, and RS scattering images were acquired for each gas. Then, 50 images of RS scattering were ensemble averaged. Finally, the averaged RS image for each gas was divided by the averaged RS image of nitrogen $\left(\mathrm{N}_{2}\right)$ in order to obtain $\sigma_{i N}$.

Temperature images using Rayleigh scattering have been acquired from the chamber at different fuel/air equivalence ratios and initial pressures. Representative images are shown in Fig. 5 and Fig. 6. In these images, the top of the almost hemispheric burned gas regions has moved about half-way through the laser sheet. The burned gas region is at the bottom and the unburned gas region is at the top of each image. The image processing shows that most combustion fronts have a small dip caused by flame wrinkle. It could be thought that the dip occurs because the $\mathrm{CH}_{4}$ burning velocity is relatively low so the spark plug geometry affects 
the flame profile and combustion-driven instabilities such as hydrodynamic instability and diffusive thermal instability occur in the premixed combustion.

In order to increase the precision of temperature measurement, small rectangles are selected that lie within uniform intensity regions of unburned and burned gases in Fig. 5 (c). Intensities inside these rectangles are averaged, respectively. Finally, RS image analysis using Eq. (5) yields $T_{b} \approx 2200 \mathrm{~K}$.

The determined temperature $T$ values for the burned gas have a certain uncertainty. The RS signal intensity of air in the whole unburned region is about 40,000 (a.u.). However, the Rayleigh intensity of burned region is about 150 (a.u.) and fluctuation of background noise level is about \pm 8 (a.u.). Therefore, the error range is $( \pm 8 / 150) \times 100= \pm 5 \%$. This error range will be larger when the temperature is increased, as RS intensity is inversely proportional to the temperature. In order to measure the temperature precisely in the burned region, the experimental system should have a high signal-to-noise ratio. Table 3 shows a summary of the measured parameters, measuring devices, measuring ranges and measurement errors in this study.

\section{CONCLUDING REMARKS}

UV Rayleigh scattering can be used to measure burning velocity and temperature distribution quantitatively and simultaneously. Laser-based RS technique with UV improves the signal-to-noise ratio compared with the longer wavelength light.

The laminar burning velocities have been calculated using pressure data through a pressure transducer and flame surface area from RS images. The flame front velocity is also measured using RS images. The constant volume combustion chamber can be a reference device for the quantitative measurements of temperature distributions via RS. 
This work has been done at a relatively low pressure with a laminar flame inside the chamber. Although none of the chamber experimental results presented here are in the range of pressure and temperature in a practical combustor, the information on laminar combustion properties is useful and is essential in the design and analysis of internal combustion engines, gas turbines and industrial burners.

\section{REFERENCES}

1. Konnov AA, Mohammad A, Kishore VR, Kim N, Prathap C, Kumar S. A comprehensive review of measurements and data analysis of laminar burning velocities for various fuel+air mixtures. Progress in Energy and Combustion Science 2018;68:197-267. https://doi.org/10.1016/j.pecs.2018.05.003.

2. Mannaa O, Mansour MS, Roberts WL, Chung SH. Laminar burning velocities at elevated pressures for gasoline and gasoline surrogates associated with RON. Combustion and Flame 2015;162:2311-2321. https://doi.org/10.1016/j.combustflame.2015.01.004.

3. Zhang Z, Huang Z, Wang X, Xiang J, Wang X, Miao H. Measurements of laminar burning velocities and Markstein lengths for methanol-air-nitrogen mixtures at elevated pressures and temperatures. Combustion and Flame 2008;155:358-368. https://doi.org/10.1016/j.combustflame.2008.07.005.

4. Metghalchi M, Keck JC. Laminar burning velocity of propane-air mixtures at high temperature and pressure. Combustion and Flame 1980;38:143-154. https://doi.org/10.1016/0010-2180(80)90046-2.

5. Metghalchi M, Keck JC. Burning velocities of mixtures of air with methanol, isooctane, and indolene at high pressure and temperature. Combustion and Flame 1982;48:191-210. https://doi.org/10.1016/0010-2180(82)90127-4.

6. Milton BE, Keck JC. Laminar burning velocities in stoichiometric hydrogen and hydrogen-hydrocarbon gas mixtures. Combustion and Flame 1984;58:13-24. https://doi.org/10.1016/0010-2180(84)90074-9.

7. Prajapati, H, Deshmukh NN. Design and development of thin wire sensor for transient temperature measurement. Measurement 2019;140:582-589. https://doi.org/10.1016/j.measurement.2019.04.020.

8. Han J, Cao K, Xiao L, Tan X, Li T, Xu L, Tang Z, Liao G, Shi T. In situ measurement of cutting edge temperature in turning using a near-infrared fiber-optic two-color 
pyrometer. Measurement 2020;156:107595.

https://doi.org/10.1016/j.measurement.2020.107595.

9. Wang Q, Jiang L, Cai W, Wu Y. Study of UV Rayleigh scattering thermometry for flame temperature field measurement. Journal of the Optical Society of America B 2019;36:2843-2849. https://doi.org/10.1364/JOSAB.36.002843.

10. Namer I, Schefer RW. Error estimates for Rayleigh scattering density and temperature measurements in premixed flames. Experiments in Fluids 1985;3:1-9. https://doi.org/10.1007/BF00285264.

11. Eckbreth AC. Laser Diagnostics for Combustion Temperature and Species. 2nd ed., Gordon \& Breach; 1996. ISBN-13: 978-9056995324

12. Kim GS, Hitchcock LM, Siegler F, Rothe EW, Tung CC, Reck GP. Planar imaging of Rayleigh and fluorescence light from $\mathrm{H}_{2}$-air combustion inside a bomb using tunable 193 nm light. Appl. Phys. 1993;B 56:139-145. https://doi.org/10.1007/BF00332193.

13. Turns S. An Introduction to Combustion: Concepts and Applications. 3rd ed., McGrawHill Education; 2011. ISBN-13: 978-0073380193

14. Reynolds WC. STANJAN chemical equilibrium solver, version 3.95, Developed and distributed by Mechanical Engineering Dept., Stanford University; 1992.

15. Bowman CT, Hanson RK, Davison DF, Gardiner WC, Lissianski V, Smith GP, et al. GRI-Mech, version 2.1 1995; http://combustion.berkeley.edu/gri-mech/.

16. Smith GP, Golden DM, Frenklach M, Moriarty NW, Eiteneer B, Goldenberg M, et al. GRI-Mech, version 3.0 1999; http://combustion.berkeley.edu/gri-mech/.

17. Kee RJ, Grcar JF, Smooke MD, Miller JA. A Fortran program for modelling steady laminar one-dimensional premixed flames. Sandia National Laboratories Report, No. SAND85-8240; 1985.

18. Kee RJ, Rupley FM, Miller JA. CHEMKIN-II: A Fortran chemical kinetics package for the analysis of gas phase chemical kinetics. Sandia National Laboratories Report, No. SAND89-8009; 1989.

19. Grcar JF, Kee RJ, Smooke MD, Miller JA. A hybrid newton/time-integration procedure for the solution of steady, laminar, one-dimensional, premixed flames. Twenty-First Symposium (International) on Combustion. The Combustion Institute, Pittsburgh; 1986, p. 1773-1782. https://doi.org/10.1016/S0082-0784(88)80411-9.

20. Egolfopoulos FN, Cho P, Law CK. Laminar flame speeds of methane-air mixtures under reduced and elevated pressures. Combustion and Flame 1989;76:375-391. https://doi.org/10.1016/0010-2180(89)90119-3.

21. Kock A, Voges H, Andresen P, Schluter H, Wolff D, Hentschel W, et al. Planar imaging of a laboratory flame and of internal combustion in an automotive engine using 
UV Rayleigh and fluorescence light. Appl. Phys. 1993;B 56:177-184.

https://doi.org/10.1007/BF00332197. 


\section{APPENDIX}

The appendix presents a calculation of the flame front surface in the constant volume combustion chamber.

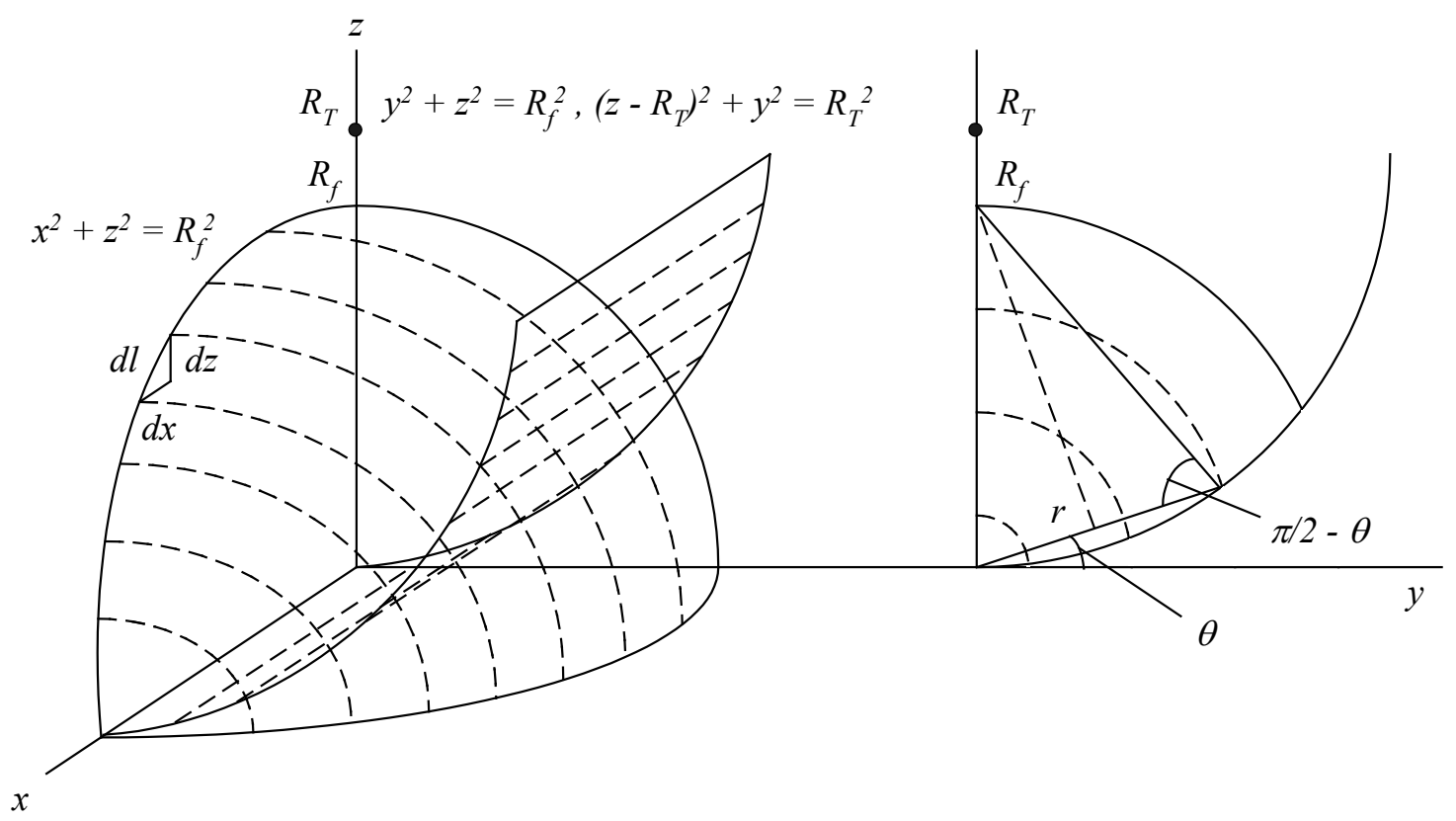

Fig. A. Geometry of the flame front surface.

Define:

$$
\begin{aligned}
& R_{T}=\text { Radius of the constant volume combustion chamber, } \\
& R_{f}=\text { Radius of the flame }
\end{aligned}
$$

Equations:

From the left side of Fig. A, we have

$$
\begin{aligned}
& x-z \text { plane }: x^{2}+z^{2}=R_{f}^{2} \\
& y-z \text { plane }: y^{2}+z^{2}=R_{f}^{2} \\
& \left(z-R_{T}\right)^{2}+y^{2}=R_{T}^{2}
\end{aligned}
$$


From the right side of the figure, we have

$$
r=2 R_{T} \sin \theta
$$

The integration element:

$$
d l=\sqrt{(d z)^{2}+(d x)^{2}}=\sqrt{1+\left(\frac{d z}{d x}\right)^{2}} \cdot d x
$$

then

$$
\frac{d z}{d x}=\frac{d}{d x}\left(\sqrt{R_{f}^{2}-x^{2}}\right)=\frac{-x}{\sqrt{R_{f}^{2}-x^{2}}}
$$

Since

$$
r=2 R_{T} \sin \theta=z
$$

we have

$$
x^{2}+\left(2 R_{T} \sin \theta\right)^{2}=R_{f}^{2}
$$

and

$$
\sin \theta=\frac{\sqrt{R_{f}^{2}-x^{2}}}{2 R_{T}}
$$

and

$$
\theta=\sin ^{-1}\left(\frac{\sqrt{R_{f}^{2}-x^{2}}}{2 R_{T}}\right)
$$

The boundary conditions are

$$
\begin{aligned}
& x=R_{f}, \quad \theta=0 \\
& x=0, \quad \theta=\sin ^{-1}\left(\frac{R_{f}}{2 R_{T}}\right)
\end{aligned}
$$

The integration element for the surface is

$$
d s=L \cdot d l
$$


where

$$
L=\left(\frac{\pi}{2}-\theta\right) \cdot z=\left[\frac{\pi}{2}-\sin ^{-1}\left(\frac{\sqrt{R_{f}^{2}-x^{2}}}{2 R_{T}}\right)\right] \cdot \sqrt{R_{f}^{2}-x^{2}}
$$

Thus

$$
\begin{aligned}
d s & =\left[\frac{\pi}{2}-\sin ^{-1}\left(\frac{\sqrt{R_{f}^{2}-x^{2}}}{2 R_{T}}\right)\right] \cdot \sqrt{R_{f}^{2}-x^{2}} \cdot \sqrt{1+\frac{x^{2}}{R_{f}^{2}-x^{2}}} \cdot d x \\
& =\left[\frac{\pi}{2}-\sin ^{-1}\left(\frac{\sqrt{R_{f}^{2}-x^{2}}}{2 R_{T}}\right)\right] \cdot R_{f} \cdot d x
\end{aligned}
$$

Finally, the surface area of the flame front is

$$
A_{f}=\int d s=\int_{-R_{f}}^{R_{f}}\left[\frac{\pi}{2}-\sin ^{-1}\left(\frac{\sqrt{R_{f}^{2}-x^{2}}}{2 R_{T}}\right)\right] \cdot R_{f} \cdot d x
$$




\section{TABLE \& FIGURE CAPTIONS}

Table 1. Mole fraction of the burned gases at different equivalence ratios and pressures.

Table 2. Normalized RS cross-sections at $248 \mathrm{~nm}$.

Table 3. Summary of the measured parameters, measuring devices, measuring ranges and measurement errors in this study.

Figure 1. Schematic of the constant volume combustion chamber and flame propagation in the chamber.

Figure 2. Laminar burning velocity of $\mathrm{CH}_{4} /$ air flames at different equivalence ratios and initial pressures.

Figure 3. Laminar burning velocity of $\mathrm{CH}_{4} /$ air flames compared with the calculated and measured values from the literature [18] at different pressures at $\phi=1.0$.

Figure 4. Flame propagation speed of $\mathrm{CH}_{4} /$ air flames at different equivalence ratios and initial pressures.

Figure 5. Temperature images at different equivalence ratios (initial press. $=1.5 \mathrm{bar}$ ).

Figure 6. Temperature images at different equivalence ratios (initial press. $=2.5 \mathrm{bar}$ ). 
Table 1. Mole fraction of the burned gases at different equivalence ratios and pressures.

\begin{tabular}{|c|c|c|c|c|c|c|c|c|c|c|c|c|}
\hline Equiv. & $\mathrm{P}$ & $\mathrm{T}$ & $\mathrm{CO}$ & $\mathrm{CO}_{2}$ & $\mathrm{H}$ & $\mathrm{OH}$ & $\mathrm{H}_{2}$ & $\mathrm{H}_{2} \mathrm{O}$ & NO & $\mathrm{N}_{2}$ & $\mathrm{O}$ & $\mathrm{O}_{2}$ \\
\hline Ratio & [bar] & {$[\mathrm{K}]$} & \multicolumn{10}{|c|}{ Mole fraction $\left(x_{i}\right)$} \\
\hline 0.7 & 2.291 & 2211 & $1.22 \mathrm{E}-3$ & $6.71 \mathrm{E}-2$ & $8.52 \mathrm{E}-5$ & $3.49 \mathrm{E}-3$ & 4.64E-4 & $1.34 \mathrm{E}-1$ & $6.74 \mathrm{E}-3$ & $7.31 \mathrm{E}-1$ & $4.47 \mathrm{E}-4$ & $5.50 \mathrm{E}-2$ \\
\hline 0.8 & 2.154 & 2382 & $4.89 \mathrm{E}-3$ & $7.22 \mathrm{E}-2$ & $4.15 \mathrm{E}-4$ & $6.33 \mathrm{E}-3$ & $1.75 \mathrm{E}-3$ & $1.49 \mathrm{E}-1$ & $7.71 \mathrm{E}-3$ & $7.21 \mathrm{E}-1$ & $1.01 \mathrm{E}-3$ & $3.60 \mathrm{E}-2$ \\
\hline 0.9 & 2.213 & 2518 & $1.32 \mathrm{E}-2$ & $7.20 \mathrm{E}-2$ & $1.26 \mathrm{E}-3$ & $8.95 \mathrm{E}-3$ & $4.80 \mathrm{E}-3$ & $1.61 \mathrm{E}-1$ & $7.55 \mathrm{E}-3$ & $7.09 \mathrm{E}-1$ & $1.55 \mathrm{E}-3$ & $2.15 \mathrm{E}-2$ \\
\hline 1.0 & 2.311 & 2603 & $2.52 \mathrm{E}-2$ & $6.76 \mathrm{E}-2$ & $2.54 \mathrm{E}-3$ & $1.01 \mathrm{E}-2$ & $9.94 \mathrm{E}-3$ & $1.69 \mathrm{E}-1$ & $6.35 \mathrm{E}-3$ & $6.95 \mathrm{E}-1$ & $1.66 \mathrm{E}-3$ & $1.17 \mathrm{E}-2$ \\
\hline 1.1 & 2.154 & 2615 & $3.80 \mathrm{E}-2$ & $6.21 \mathrm{E}-2$ & $3.60 \mathrm{E}-3$ & $8.85 \mathrm{E}-3$ & $1.70 \mathrm{E}-2$ & $1.77 \mathrm{E}-1$ & $4.28 \mathrm{E}-3$ & $6.83 \mathrm{E}-1$ & $1.22 \mathrm{E}-3$ & $5.22 \mathrm{E}-3$ \\
\hline 1.2 & 2.057 & 2565 & $5.12 \mathrm{E}-2$ & $5.59 \mathrm{E}-2$ & $3.77 \mathrm{E}-3$ & $5.75 \mathrm{E}-3$ & $2.67 \mathrm{E}-2$ & $1.83 \mathrm{E}-1$ & $2.10 \mathrm{E}-3$ & $6.70 \mathrm{E}-1$ & $5.30 \mathrm{E}-4$ & $1.50 \mathrm{E}-3$ \\
\hline 1.3 & 2.123 & 2487 & $6.52 \mathrm{E}-2$ & $4.81 \mathrm{E}-2$ & $3.29 \mathrm{E}-3$ & $3.00 \mathrm{E}-3$ & $4.09 \mathrm{E}-2$ & $1.83 \mathrm{E}-1$ & $8.08 \mathrm{E}-4$ & $6.56 \mathrm{E}-1$ & $1.59 \mathrm{E}-4$ & $2.96 \mathrm{E}-4$ \\
\hline
\end{tabular}


Table 2. Normalized RS cross-sections at 248nm.

\begin{tabular}{cccc}
\hline Gases $i$ & $\alpha^{\mathrm{a}}{ }_{\mathrm{i}}$ & $\sigma_{\mathrm{iN}}^{\mathrm{a}}$ & $\sigma_{\mathrm{iN}}$ \\
\hline $\mathrm{N}_{2}$ & 1.94 & 1.00 & 1.00 \\
$\mathrm{O}_{2}$ & 1.80 & 0.89 & 0.84 \\
$\mathrm{H}_{2} \mathrm{O}$ & 1.69 & 0.75 & \\
$\mathrm{CO}_{2}$ & 2.91 & 2.25 & 2.36 \\
$\mathrm{CH}_{4}$ & & & 2.29 \\
\hline $\begin{array}{l}\text { a: }[21] . \text { The difference between authors' and previous } \\
\text { publication is mainly due to the optical setup. }\end{array}$
\end{tabular}


Table 3. Summary of the measured parameters, measuring devices, measuring ranges and measurement errors in this study.

\begin{tabular}{cccc}
\hline $\begin{array}{c}\text { Measurement } \\
\text { parameters }\end{array}$ & $\begin{array}{c}\text { Measurement } \\
\text { devices/technique }\end{array}$ & $\begin{array}{c}\text { Measurement } \\
\text { range }\end{array}$ & $\begin{array}{c}\text { Measurement } \\
\text { error }\end{array}$ \\
\hline Pressure & $\begin{array}{c}\text { Piezoelectric } \\
\text { transducer }\end{array}$ & $0-7$ bars & $\pm 1 \%$ \\
Burning velocity & RS & up to a few km/s & $\pm 3 \%$ \\
Temperature & RS & $\begin{array}{c}\text { up to several } \\
\text { thousand degrees } \mathrm{K}\end{array}$ & $\pm 5 \%$ \\
\hline
\end{tabular}



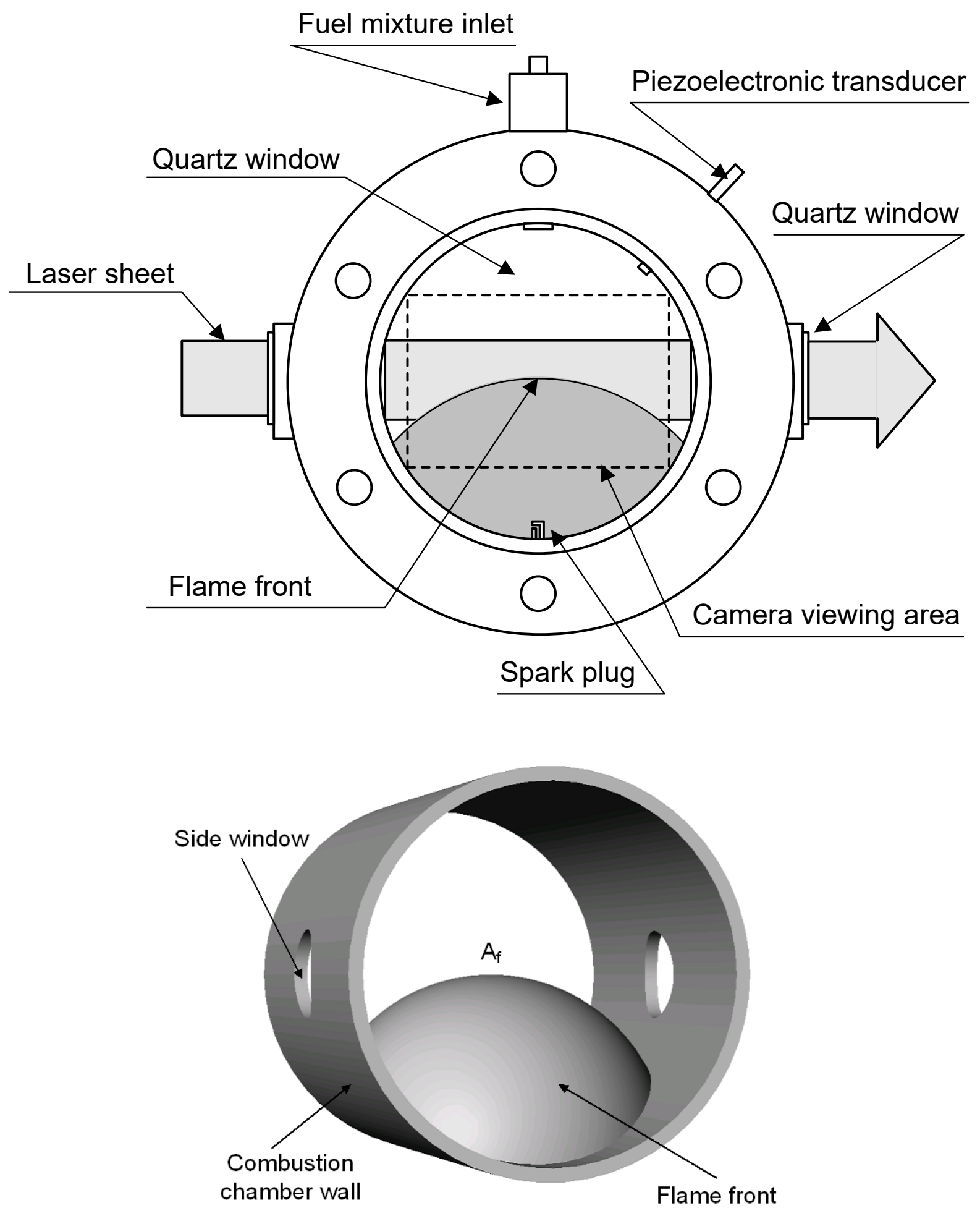

Figure 1. Schematic of the constant volume combustion chamber and flame propagation in the chamber. 


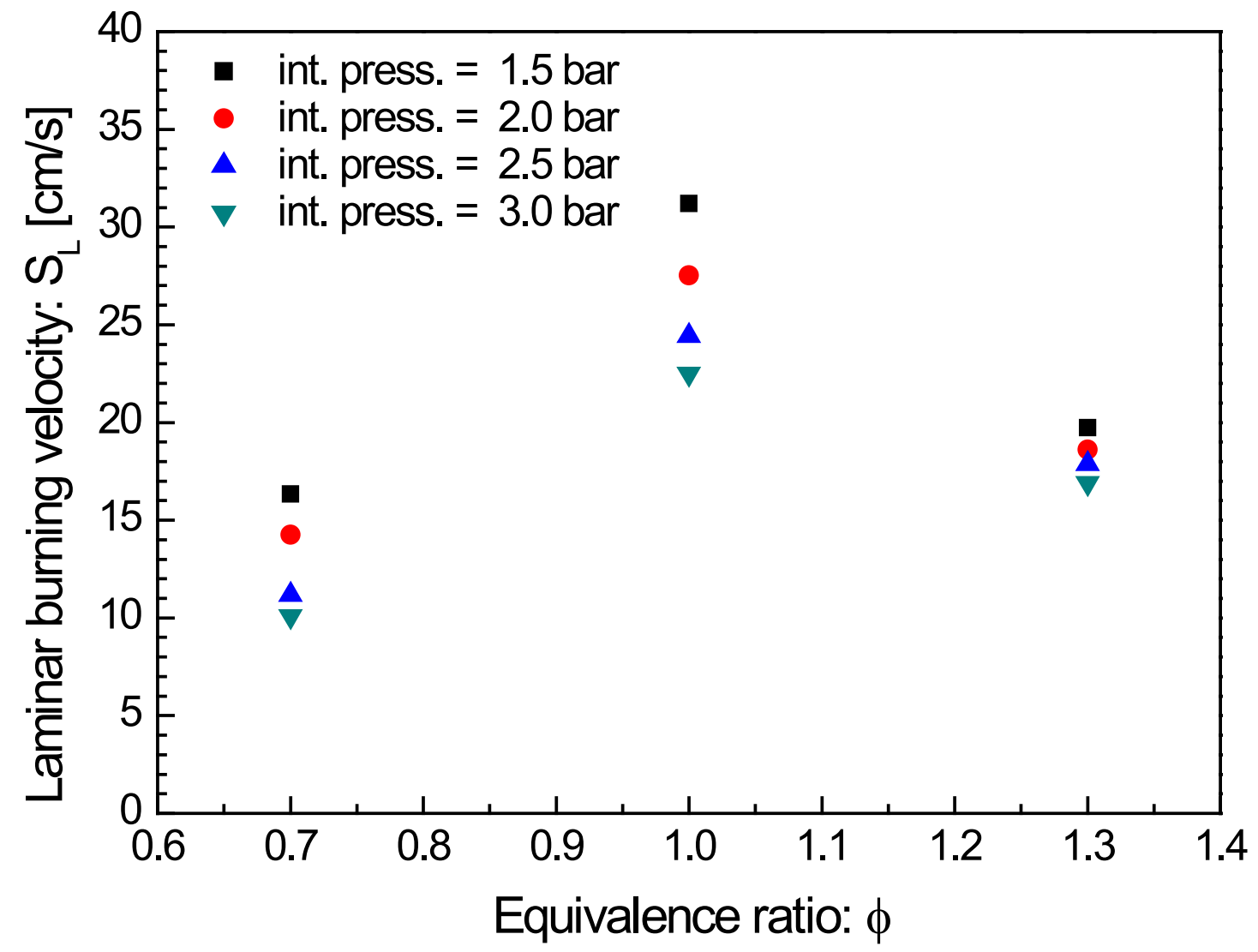

Figure 2. Laminar burning velocity of $\mathrm{CH}_{4} /$ air flames at different equivalence ratios and initial pressures. 


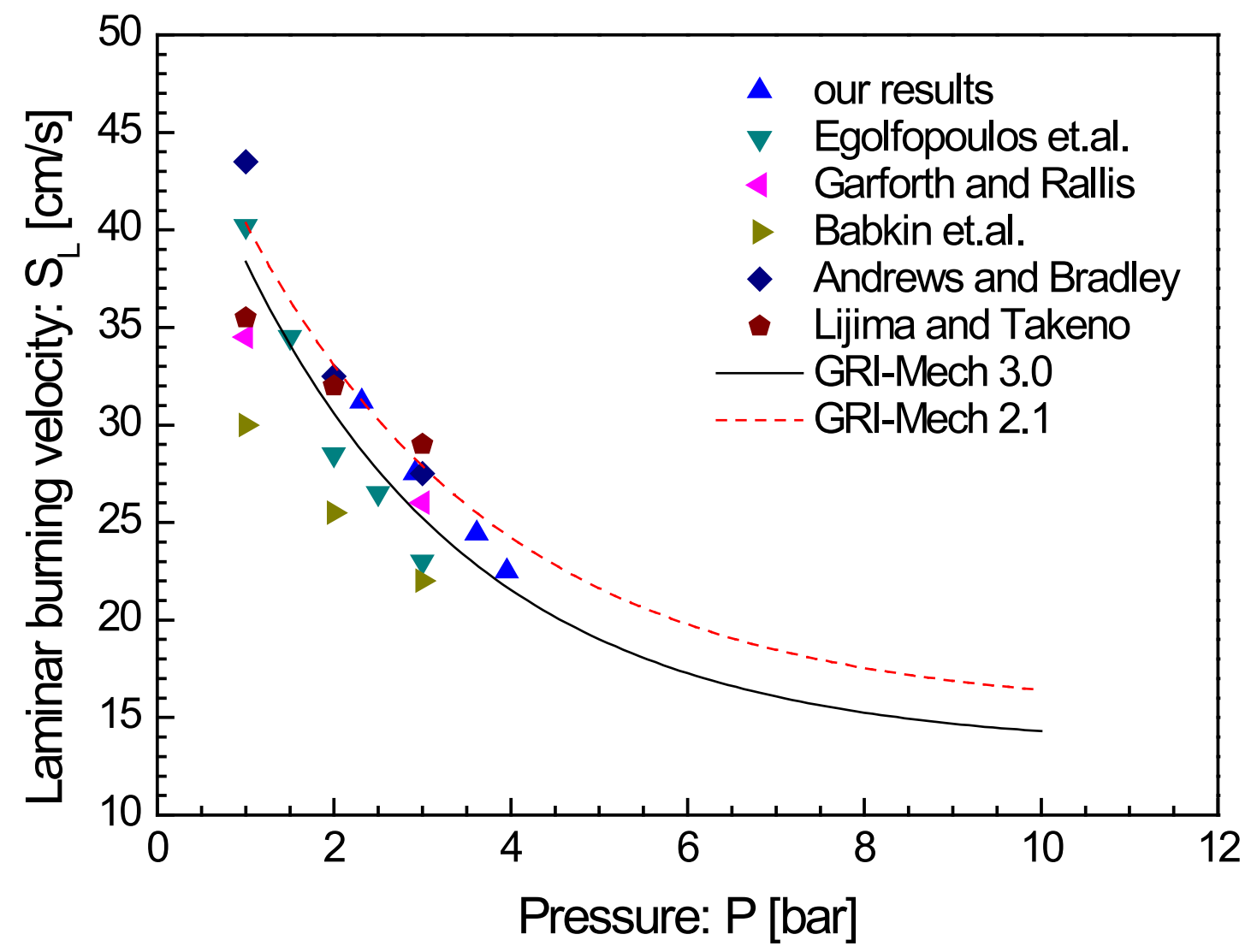

Figure 3. Laminar burning velocity of $\mathrm{CH}_{4} /$ air flames compared with the calculated and measured values from the literature [18] at different pressures at $\phi=1.0$. 


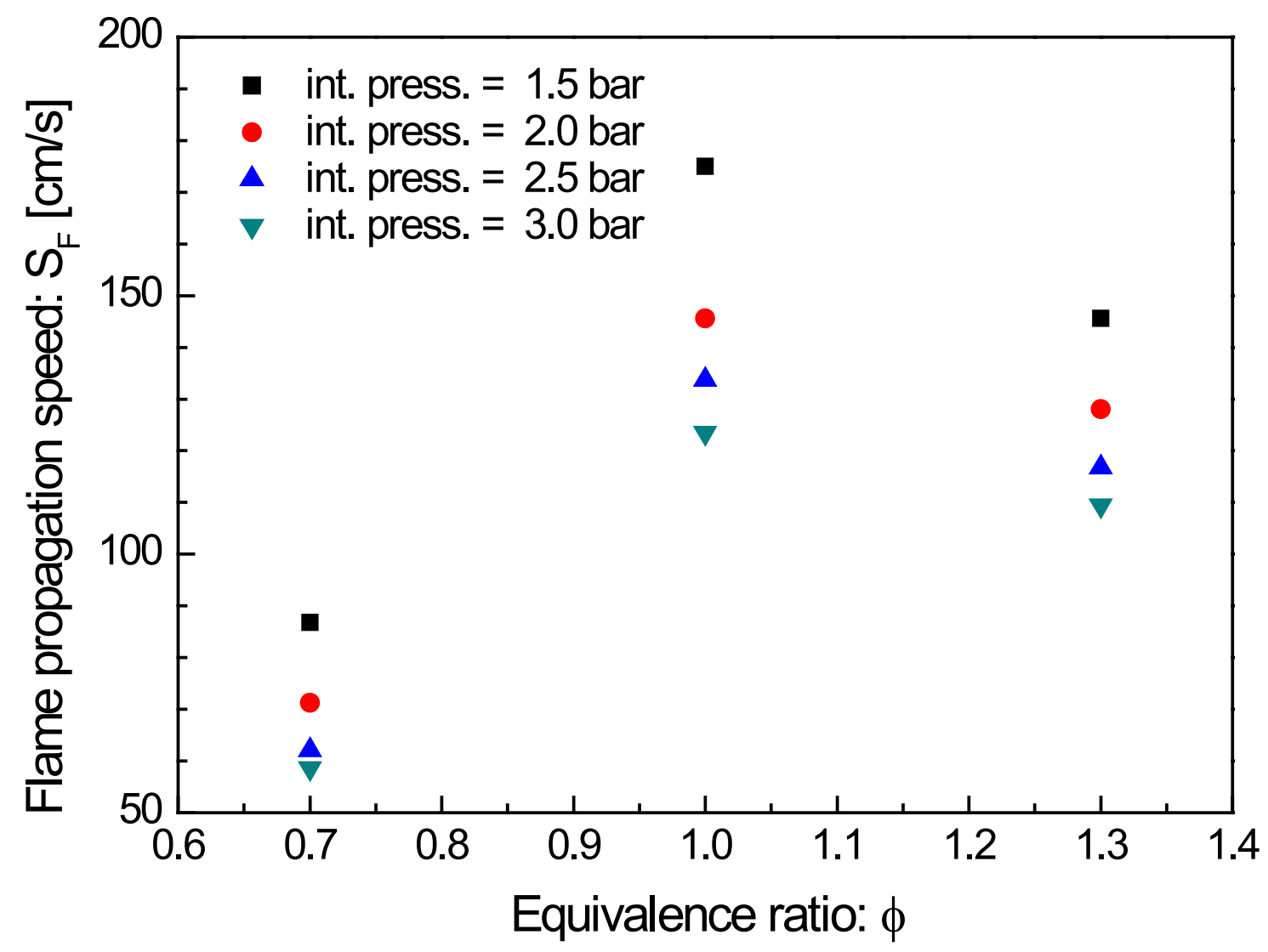

Figure 4. Flame propagation speed of $\mathrm{CH}_{4} /$ air flames at different equivalence ratios and initial pressures. 

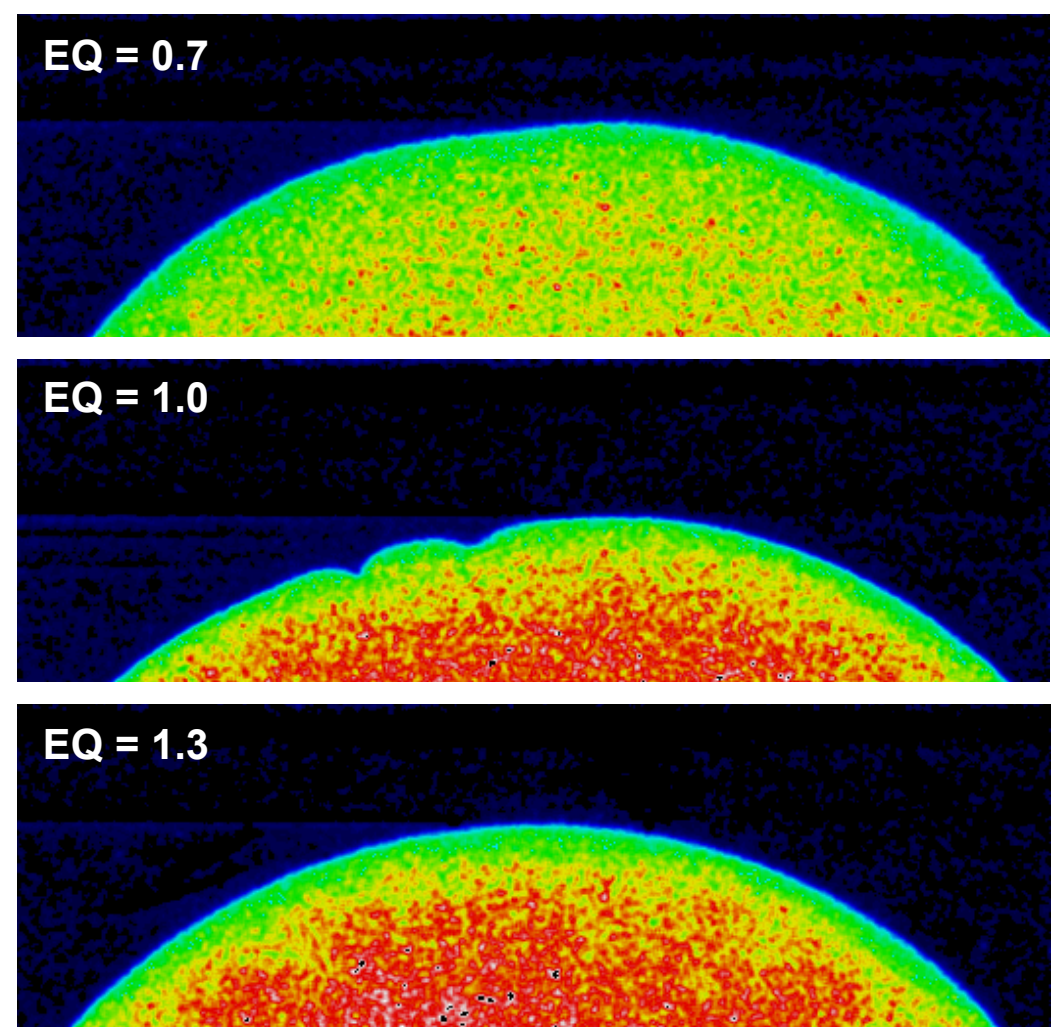

Figure 5. Temperature images at different equivalence ratios (initial press. $=1.5$ bar). 

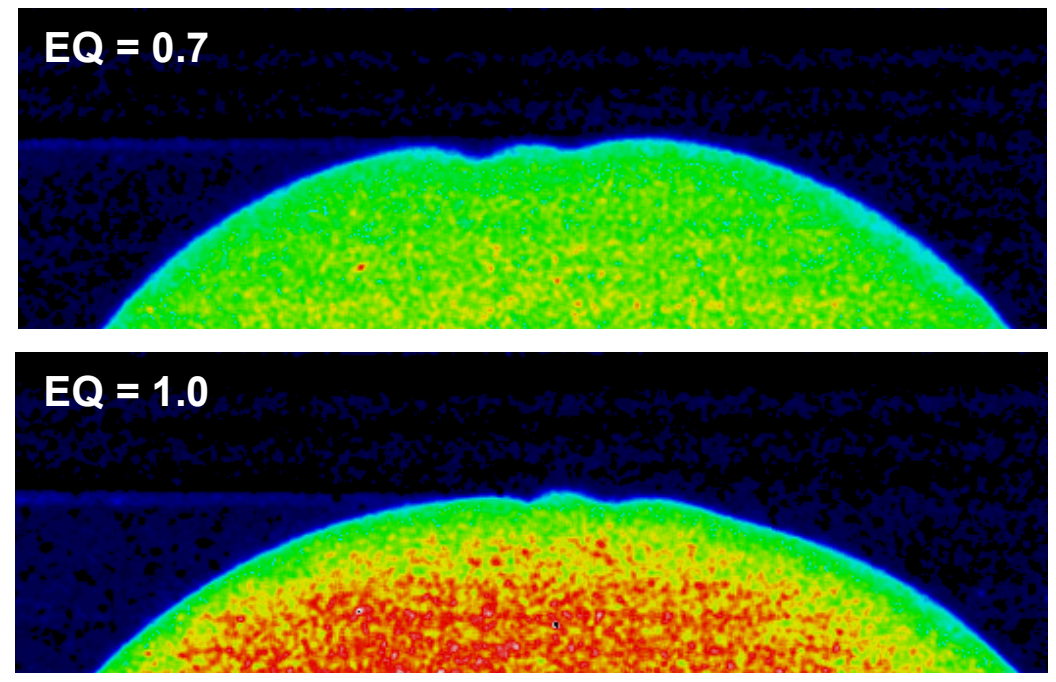

$$
E Q=1.3
$$

Figure 6. Temperature images at different equivalence ratios (initial press. $=2.5$ bar). 


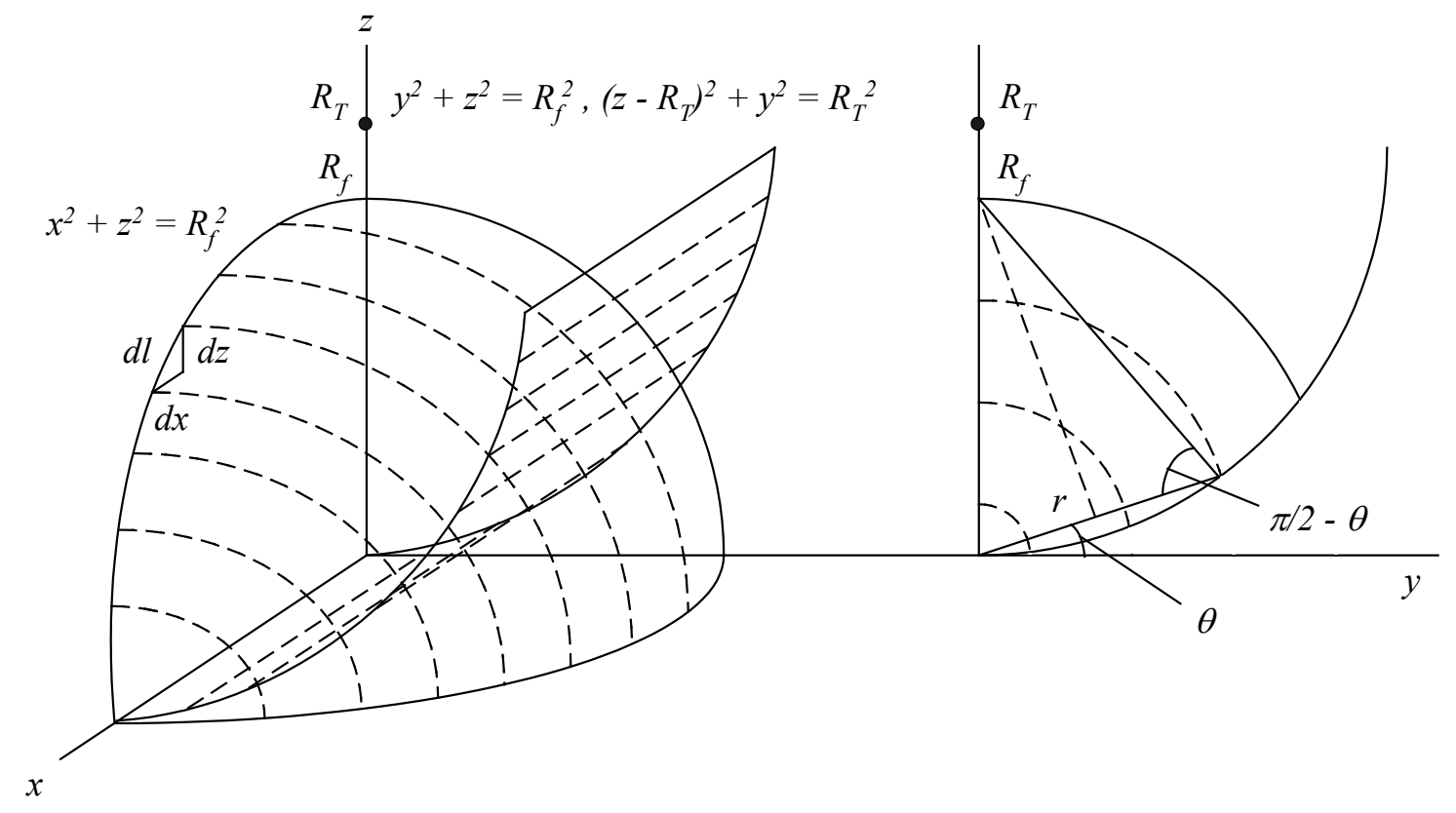

Fig. A. Geometry of the flame front surface. 